\title{
Ideia sensível e imagem pictórica: a articulação dos gêneros artísticos na estética alemã
}

Oliver Tolle

oliver.tolle@gmail.com

Universidade de São Paulo (USP), São Paulo Brasil

resumo A analogia entre pintura e poesia, tal qual sugerida na Carta aos Pisões de Horácio, não foi interpretada de modo homogêneo pela estética alemã do começo do século XVIII. Como tentaremos mostrar, em alguns autores essa analogia está muito mais atrelada ao caráter sensivel como um todo da arte do que propriamente a uma referência imagética. Por um lado, isso pode ser constatado na obra crítica de Gottsched, que procura atenuar a importância do aspecto descritivo na poesia. Encontramos, por outro lado, na investigação teórica de Baumgarten uma abordagem segundo a qual o que une as diversas artes não é o seu compromisso com o sentido da visão ou mesmo a primazia da imagem pictórica sobre o discurso poético, mas sim o de estarem situadas naquele plano que definiu como abaixo do limiar da razão.

palavras-chave estética alemã; artes plásticas; poética; psicologia empírica; filosofia alemã; iluminismo

Ut poesis, pictura non erit.

Diderot

No prefácio de seu Laocoonte de 1766, Lessing observa que a aproximação de poesia e pintura tão em voga entre seus contemporâneos foi longe demais. Ela se converteu em uma norma que postula a orientação imagética da poesia e a importância da fábula (história) para a pintura. Desse modo, a analogia que se tornou tão famosa graças à expressão horaciana ut pictura poesis [assim na poesia como na pintura] deixou de corresponder 
à intenção originária que a motivou, pois não escapara já aos antigos que "a despeito da completa semelhança do efeito" dos dois gêneros artísticos, "tanto nos seus objetos como na espécie de sua imitação [os dois] eram diferentes". Antes de Lessing, Shaftesbury também chamara a atenção para o fato de que "[...] comparações e paralelos feitos entre pintura e poesia por causa do pictoribus atque poetis [pintores e poetas] etc. e o ut pictura poesis [poemas são como pinturas] são quase sempre absurdos e, na melhor das hipóteses, limitados, desajeitados e deficientes" (SHAFTESBURY, 1914, p. 141). Como se sabe, Lessing tem em mente aqui a obra de Winckelmann, o qual responsabiliza pela "mania descritivista na poesia e pelo caráter alegorizante da pintura” (LESSING, I - Prefácio). Ora, gostaríamos de mostrar no presente texto que a aproximação entre pintura e poesia no século XVIII não obedeceu sempre a essa tentativa de subordinação de um gênero ao outro. $\mathrm{Na}$ verdade, o problema da fundamentação filosófica que moveu a primeira metade do século é responsável por uma recepção muito menos normativa da poética horaciana do que o Laocoonte pode dar a entender.

É, aliás, o próprio Lessing quem adverte sobre o terreno em que a comparação entre pintura e poesia pode possuir alguma validade, quando define com precisão dois âmbitos diferentes da consideração do objeto artístico, os quais se constituirão cada vez mais como polos de uma mesma disciplina: a filosofia da arte e a crítica de arte. Para Lessing, que se considera ele mesmo um "juiz da arte", se a crítica não pode se dar por satisfeita com comparações simplistas que postulam a primazia da imagem pictórica sobre o discurso poético, não deixa de ser natural que a filosofia, que considera o problema da aparência do objeto artístico, enfrente o mesmo princípio a partir de uma perspectiva mais universal ou, o que no caso dos autores metafísicos quer dizer o mesmo, teórica.

$* * *$

Antes de passarmos para uma consideração mais filosófica da comparação entre poesia e pintura, gostaríamos de examiná-la segundo a obra de um poeta que pensou o seu ofício e, portanto, se aproxima mais do crítico do que do filósofo, ou seja, pensa a si mesmo mais como um Horácio do que 
como um Aristóteles, embora esteja vinculado teoricamente à filosofia de Leibniz e a assim chamada Escola de Wolff. Ao publicar sua Tentativa de uma crítica poética em 1730, Johann Christoph Gottsched deixa claro estar inteiramente a par da discussão sobre o caráter normativo das poéticas clássicas, e em particular sobre o seu significado mais prático do que teórico. Como ele diz a propósito da tradução de próprio punho para o alemão da Poética de Horácio, com a qual abre a obra e faz acompanhar de um grande número de notas explicativas:

Ninguém deve pensar que o poeta [Horácio] quis realizar aqui uma obra sistemática e completa. Os seus maiores admiradores estão de acordo quanto a ter sido escrita sem qualquer ordem, sim, em ela não compreender nem remotamente todas as regras que pertencem à poesia. $\mathrm{O}$ autor não quis se prender a nenhuma obrigação decorrente de uma orientação filosófica; ao contrário, como poeta, expressou ora essa, ora aquela regra em versos segundo um modo de escrever nobre, explicando-a com exemplos de bons e maus poetas. Mas tudo o que ele diz é sumamente razoável, e não é possível se afastar nenhum palmo de suas prescrições, sem ao mesmo tempo se afastar da verdade, da natureza e da razão sadia. A mistura desordenada de suas regras serve apenas para que, por meio dessa multiplicidade e alternância impensada de questões, o leitor seja tanto mais entretido. (GOTTSCHED, 1730, Informe preliminar)

Gottsched informa ainda que a sua tradução da Poética para o alemão não se destina àqueles cujo gosto já se encontra desenvolvido - e que, portanto, já estão familiarizados com as regras da composição -, mas sim aos iniciantes. Assim como Horácio se sentiu compelido a escrever em virtude "da grande quantidade de poetas ruins na Roma" de sua época, de igual maneira também a obra de Gottsched pretende ser de auxílio para o desenvolvimento da poesia alemã. Nesse contexto, poderia se esperar que Gottsched se valesse do suposto princípio horaciano da primazia da pintura sobre a poesia ou, em outras palavras, da exigência de que a poesia seja descritiva, para facilitar o caráter didático da sua obra. Pois, como é de se esperar, Gottsched entende que o poeta, assim como o pintor, são imitadores da natureza, o que deixa claro na seguinte passagem:

Um poeta é um imitador da natureza, se posso me expressar assim; e, na verdade, ele deve ser um imitador instruído, como diz Horácio, ou seja, 
um pintor habilidoso e exercitado. (GOTTSCHED, 1730, Sobre a arte poética - nota 124)

Com base nisso, podemos concluir que, para Gottsched, o êxito do poeta como imitador reside na sua capacidade de produzir, por meio do poema, imagens pictóricas convincentes, tal como na parábola dos pintores Zêuxis e Parrásios? Uma leitura mais detida da obra de Gottsched rapidamente mostra a fragilidade dessa hipótese - e também que supor tal interpretação da poética horaciana no começo do XVIII pode ser um procedimento investigativo temerário. Numa nota redigida para a tradução do texto de Horácio, a propósito justamente do emprego excessivo de imagens, somos advertidos de que o recurso à imagem deve se pautar pela parcimônia:

[...] Uma descrição vivida é suficiente; mas puras imagens e descrições produzem uma leitura fastidiosa. Por que ainda são publicados ainda livros inteiros de tais pinturas poéticas? - como se a principal obra de toda a arte poética tivesse algo a ver com isso. (GOTTSCHED, 1730, Sobre a arte poética - nota 7)

Como entender essa restrição ao uso da imagem pictórica? De certo modo, já Horácio pensava a imagem como um recurso de valor limitado para o poeta, mas Gottsched pretende ir um pouco além disso. Para ele, a comparação entre pintura e poesia deve ser vista também sob a ótica da diferença. Ele exemplifica isso quando comenta numa nota a famosa comparação, tomando-a não como excerto, mas em sua versão integral [Ut pictura, poesis erit, quae, si proprius stes te capiet magis, E quaedam, si longius abstes. Tradução: Um verso é semelhante a imagens: algumas nos agradam quando são examinadas e vistas de perto, ao passo que outras se mostram excelentes apenas à distância.]

Um verso é semelhante a imagens: algumas nos agradam quando são examinadas e vistas de perto, ao passo que outras se mostram excelentes apenas à distância. Dacier ${ }^{1}$ explica isso também para boas poesias, e acredita que alguns bons versos permanecem válidos depois de um bom exame, mas outros devem ser vistos apenas de relance. Isso tem sua pertinência para pinturas: mas com versos é de maneira bem diferente. Um poema que não resiste ao exame de um crítico convence tão pouco 
quanto o ouro que resiste a ser marcado. A símile de Horácio deve ser compreendida para aquelas imagens que no escuro ou de longe parecem ser belas, mas de fato são ruins; pois há aquelas que exibem muito mais belezas quanto mais e com mais cuidado são examinadas. (GOTTSCHED, 1730, Sobre a arte poética - nota 142)

Qual a ênfase aqui? Que a poesia, ao contrário da pintura, não quer produzir apenas ilusões de realidade e, quando recorre pura e simplesmente à imagem para produzir a ilusão, torna-se de qualidade inferior. $O$ juiz da arte rapidamente reconhece essa deficiência. Devemos, portanto, entender imitação da natureza em um sentido mais amplo que aquele de simplesmente produzir, por meio da poesia, uma imagem vívida, tal como produz o pintor.

Como um pensador do racionalismo tardio, Gottsched retoma uma ideia cara a Leibniz, que pensa a arte não como imitação imagética, e sim como imitação sensível da natureza. ${ }^{2}$ Ou seja, que o artista, ao exercer a sua capacidade de imitar a natureza, não se dirige ao sentido da visão em particular ou reconhece no conteúdo visual uma síntese aceitável do sensível. Gottsched deixa claro isso ao ampliar o poder pictórico do poeta quando comparado ao do pintor:

[...] tal pintura de um poeta se estende muito mais longe que a arte ordinária da pintura. Essa só pode pintar para os olhos, o poeta, ao contrário, pode fazer descrições para todos os órgãos dos sentidos [Sinne]. (GOTTSCHED, 1730, I - 4 S 1)

Há alguns caminhos que podem ajudar a entender melhor que o que efetivamente sustenta em Gottsched a aproximação entre visão e sensibilidade não é a suposição de que a visão é o sentido mais apropriado para a compreensão do sensível, o que por si só é problemático no contexto da teoria da harmonia preestabelecida. Vamos nos deter apenas em um deles, forte o suficiente para os nossos propósitos. Ele diz respeito à relação entre gosto e artes liberais. Para Gottsched - que retoma aqui uma discussão muito em voga na sua época - o gosto pelo seu sentido ordinário [em alemão: Geschmack - paladar] e pelo seu sentido metafórico [ou seja, como juízo - "gosto de determinada música, desgosto da pintura de fulano"]. Gottsched explica que assim como a visão é empregada 
nas ciências demonstrativas como metáfora do conhecimento elevado (conhecimento claro, obscuro etc.), o gosto se aplica ao conhecimento que adquirimos ao considerar as coisas sensíveis ou mais especificamente seus produtos mais elaborados, as artes liberais, a partir do seu significado como paladar. Por isso, não funciona muito bem aplicar, ainda que de maneira metafórica, o juízo sensível (gosto), dado o seu caráter subjetivo, a essas ciências "mais rigorosas":

A respeito do gosto metafórico de nossas almas observa-se que essa palavra é usada quase que exclusivamente nas artes liberais e outras coisas sensíveis; ao contrário, onde se trata tão-somente da razão, ali não se tem o hábito de utilizar a palavra. O gosto é um termo muito conhecido na poesia, na eloquência, na música, na pintura e na arquitetura e de igual maneira no vestuário, na jardinagem, em questões domésticas etc. Mas jamais ouvi falar dele na aritmética e na geometria ou em outras ciências em que se é capaz de obter as demonstrações mais rigorosas a partir de verdades fundamentais conhecidas. Nessas ciências, contudo, em que o distinto e o indistinto, o provado e o não provado, ainda se encontram misturados, ali ainda constitui um hábito falar de gosto. Por exemplo, eu posso dizer: um livro de teologia ao sabor de Mosheim, um direito natural segundo o gosto de Puffendorf, um remédio ao gosto de Boerhaven. Mas nesses casos devo observar que se procura o termo gosto nas partes dessas disciplinas que ainda são incertas e que, portanto, ainda não gozam de aceitação geral. Logo que isso é alcançado e uma questão é considerada como algo demonstrado, então imediatamente ela deixa de ser relacionada com o gosto. Assim, astrônomos não podem mais dizer "uma astronomia ao sabor de Copérnico", porque esse sistema é reconhecido e aceito em todos os lugares como o único verdadeiro. (GOTTSCHED, 1730, I-3\$6)

A partir disso, Gottsched pode afirmar que é próprio às artes liberais, justamente porque são sensíveis e de algum modo confusas, estarem no âmbito do gosto, isto é, no sentido metafórico do termo, porque a escolha de um objeto ou de outro depende também de fatores inconscientes, já que não é possível explicar inteiramente os motivos da escolha. Nas ciências demonstrativas, ao contrário, a escolha se baseia em regras conhecidas clara e distintamente. 
O uso metafórico do termo "gosto" para as artes liberais e da expressão "ver claramente" para as ciências demonstrativas conduz à distinção entre o juízo próprio a cada uma delas: apenas nas últimas é que conheço as regras que sustentam o juízo, ou seja, posso proceder racionalmente. Isso conduz a uma outra questão, particularmente importante para todo o XVIII, que é justamente a de tentar estabelecer as regras das artes liberais, para que elas deixem de ser avaliadas pelo gosto e sejam, por assim dizer, conhecidas. Se Gottsched é um daqueles que acredita que a confusão entre o conhecimento fundado no gosto e o conhecimento fundado em regras é a mãe de todos os males, outros autores defenderão que é próprio ao sensível não poder ser conhecido inteiramente por regras, mas gostaríamos de tratar disso em outro lugar. Aqui basta dizer que o conhecimento em geral, seja ele inconsciente ou racional, se relaciona com os sentidos (visão, paladar etc.) apenas metaforicamente e que não serve nem mesmo como critério para distinção entre as artes liberais.

$* * *$

A dificuldade em interpretar o verdadeiro significado da comparação de pintura e poesia se repete com outro autor que pensou a Poética de Horácio no começo do século XVIII: Alexander Gottlieb Baumgarten. Contudo, ao contrário de Gottsched, Baumgarten se aproxima de Horácio não com o nobre propósito de auxiliar na composição de poemas e assim fomentar o desenvolvimento da poesia nacional alemã, mas para fundamentar suas regras filosoficamente, ou seja, explicá-las a partir da metafisica.

Ao lermos o $\$ 39$ de seu Algumas considerações filosóficas sobre o poema (1735), a primeira impressão é a de que estamos efetivamente diante da interpretação usual do princípio horaciano de que a poesia busca na pintura o referencial imagético:

É próprio da pintura representar o que é composto; e este procedimento é um procedimento poético. A representação deve ser muito semelhante à ideia sensível do objeto que queremos pintar; e esta mesma tarefa cabe à poesia. Logo, um poema e uma pintura são semelhantes. Ut pictura poesis. [BAUMGARTEN, 1735, \39] 
Ora, essa interpretação pode ser perigosamente apressada. No parágrafo seguinte, Baumgarten demonstra não concordar tão rápido com a primazia da pintura sobre a poesia. Para ele, o que há de comum entre ambos os gêneros artísticos é o vínculo com a ideia sensível e não necessariamente com uma imagem. $\mathrm{Na}$ verdade, a imagem pictórica, quando comparada à poética, possui um efeito muito mais limitado.

A pintura representa as imaginações somente na superfície; portanto, sua tarefa não inclui representar toda a situação, nem representar o movimento; em compensação, esta tarefa cabe à poesia [...]. Logo, nas imagens poéticas há mais elementos contribuindo para a unidade das mesmas que nas imagens pictóricas. Consequentemente, um poema é mais perfeito que uma pintura. [...] [BAUMGARTEN, 1735, \40]

Somos obrigados a nos perguntar aqui qual é então o sentido de Baumgarten proceder a um exame da Poética de Horácio à luz da metafisica leibniziana no Algumas considerações sobre o poema se ele não aceita esses princípios como normas rígidas e tampouco os organiza hierarquicamente. Ao nosso ver, isso deve, como em Gottsched, ao conceito leibniziano de ideia sensível, que confere uma outra dimensão ao problema da articulação entre os gêneros artísticos. Pois não é que as diversas maneiras de expressão artística estejam articuladas em torno de algo como a essência da arte, como por exemplo, o referencial imagético ou a capacidade de proporcionar a fruição de uma totalidade (fábula) - o que permitiria uma remissão modelar ao princípio horaciona. Embora, o Algumas considerações não possa responder satisfatoriamente a essa questão, ele parece já indicar que a fundamentação dos princípios parte de um conjunto muito mais amplo de objetos do que a mera contraposição entre pintura e poesia, mas apenas com a obra Estética, publicada em 1750/58, ficará claro que é no âmbito de uma ciência em geral do sensível que se pode afirmar que as faculdades inferiores do conhecimento (sensíveis) são postas em movimento ou exercitadas não por este ou aquele gênero, mas sim que cada um deles produz um conjunto de efeitos particulares na sensibilidade.

Já nas primeiras páginas da Estética, o leitor é convidado a expandir o horizonte do objeto artístico para todos os gêneros artísticos: Baumgarten afirma ali categoricamente que a obra "fornecerá princípios adequados para todas as pretensões de abrandamento dos costumes e todas as artes 
liberais" (BAUMGARTEN, 1750, \ 3). A Estética contrasta desse modo com o mencionado Algumas considerações filosóficas sobre o poema, uma vez que nele encontramo-nos limitados ao âmbito do discurso sensível perfeito, isto é, à poesia. Segundo a definição da amplitude do objeto investigado pela Estética, aparentemente estamos diante uma teoria geral das belas-artes. Mas apesar desse anúncio inicial, a Estética se deterá apenas na praticamente apenas na poesia e na oratória. A pintura, a música e demais gêneros artísticos aparecerão apenas de maneira secundária nas demais páginas da obra. Como artes, elas ganharão autonomia quando se constituírem como um sistema nas filosofias da arte do começo do XIX. Esse fato, contudo, conduz falsamente à conjectura de que também a Estética é uma poética de inspiração horaciana parecida com o Algumas considerações sobre o poema. Por um lado, também aqui não é válida por si mesma a regra de que a poesia deve produzir no leitor imagens, isto é, que ela segue o modelo pictórico. Por outro, a despeito de ela privilegiar a investigação do discurso, é uma obra que declara expressamente que o vínculo entre a diversidade de artes e gêneros é a remissão à ideia sensível, e de tal modo que essa ideia seja conduzida à sua totalidade - o que significa que ela se torna um conhecimento verdadeiro.

E tampouco é aqui o caso de inverter o princípio horaciano. A poesia também não pode se servir do referencial para a pintura ou outro gênero artístico unicamente porque é a mais perfeita das artes. Isso se deve ao fato de que, para Baumgarten, cada uma das artes liberais estimula de um modo particular os órgãos sensíveis e, portanto, não pode ser substituído por outro, mais importante. Assim, para Baumgarten, o exercício das faculdades inferiores do conhecimento exige vivência não apenas desta ou daquela arte, porque cada uma delas promove um tipo diferente, mas necessário, de emulação do sensível: "histórias, situações heroicas, sejam elas trágicas ou cômicas, música, dança, pintura” (BAUMGARTEN, 1750, \ 83)

$* * *$

Muitos outros autores da estética alemã que pensaram o belo e as artes no XVIII podem ajudar a fomentar a suposta simplicidade da analogia. Em seu Teoria geral das belas-artes, por exemplo, Sulzer afirma que a passagem 
da linguagem pictórica para a poética é facultada pelo princípio horaciano ut pictura poesis (assim na poesia como na pintura), o que de certo modo pressupõe a orientação imagética da poesia. Assim, esse princípio pictórico permitiria um livre trânsito entre os gêneros artísticos, isto é, a partir do seu caráter imagético, como se mostra numa sugestiva passagem do seu dicionário enciclopédico:

É possível pintar não apenas para o olho, mas também tão-somente para a imaginação e inclusive para o ouvido. O primeiro é realizado pelos poetas, o último pelos músicos. O poeta pode ilustrar objetos visíveis de tal maneira que acreditamos ter uma pintura diante de nossos olhos. (SULZER, verbete: Malerei, 1771-74)

É fácil perceber aqui que o significado da palavra "imagético" ou "pictórico" é muito mais amplo do que o de mera "descrição" que está na base da crítica de Lessing a Winckelmann. Isso significa que, para Sulzer, a poesia deve suscitar, por meio de palavras, na mente do leitor impressões tão intensas como aquelas que o pintor reproduz em suas telas, mas as impressões não estão vinculadas ao seu caráter "imagético" e sim ao "sensível" e, mais do que isso, de um sensível criado e não necessariamente experimentado. Isso fica claro no verbete "Faculdade de compor":

Capacidade de produzir representações dos objetos dos sentidos e da sensação interna, que jamais foram percebidas diretamente. Cada homem possui essa capacidade em maior ou menor grau [...]. Como [as artes] não representam esses objetos sensíveis tal como os receberam da experiência, mas como elas gostariam de tê-los percebido com um efeito mais vívido, então precisam possuir certo grau de habilidade para configurar tais objetos segundo as suas intenções. [...] Por isso não é também sem motivo que em nossa língua o nome "poeta [compositor, Dichter]" é atribuído ao [domínio de um gênero], embora ele se refira também aos artistas [de] outros [gêneros]. (SULZER, verbete:

Dichtungskraft, 1771-74)

Por trás dessa interpretação da analogia entre as artes, é preciso dizer agora, opera a tomada de modelo da poesia grega de Homero, compreendida como a mais de linguagem mais concreta, isto é, não só mais próxima do referencial imagético como do sensível em geral, a despeito da ironia 
de ter sido composta por um cego, aspecto que será enfatizado posteriormente por Herder. De fato, a relativa ausência de termos e referenciais abstratos na poesia grega a tornará em diversos momentos do século XVIII modelo para uma arte comprometida com a expressão sensível do mundo e para compreensão de que obras de arte autênticas são suporte de um significado absoluto e concreto, devolvendo o homem ao solo de que jamais deveria ter sido retirado pela obsessão filosófica de explicar o transcendente antes de alcançar uma compreensão sensível do mundano.

${ }^{1}$ André Dacier (1651-1722) tradutor da Poética de Horácio para o francês.

${ }^{2}$ A propósito da concepção leibniziana de arte, ver:Tolle, O. Perfeição e beleza como atributos da Sabedoria Universal.Viso, n. 9, jul-dez/2010.

\section{Referências bibliográficas}

BAUMGARTEN, A.G. 2007. Ästhetik. (Band 1: SS 1-613) Lateinischdeutsch. Übersetzt, mit einer Einleitung und Anmerkungen hrsg. von Dagmar Mirbach. Meiner Verlag, Frankfurt.

2007. Ästhetik. (Band 2: \$S 614-904) Lateinisch-deutsch.

Übersetzt, mit einer Einleitung und Anmerkungen hrsg. von Dagmar Mirbach. Meiner Verlag, Frankfurt.

1735. Meditationes philosophicae de nonnullis ad poema

pertinentibus. Halle, Grunert.

1739. Metaphysica. Halle, Hemmerde.

1741. Philosophische Brieffe von Aletheophilus. Frankfurth und

Leipzig.

1750/58. Aesthetica. Frankfurt, Kleyb.

FORSTER, M.N. 2010. "Herder's importance as a philosopher". In: Forster, Michael N. After Herder. Oxford University Press. 
HERDER, J.G. 1994. Schriften zu Philosophie, Literatur, Kunst und Altertum (1774-1787). Editado por Jürgen Brummack e Martin Bollacher. Frankfurt am Main: Deutscher Klassiker Verlag. ."Monumento a Baumgarten". In: A palo seco - Escritos de Filosofia e Literatura, ano 2, n. 2, 2010, pp. 58-65.

HORÁCIO. 2005. “ $A$ arte poética”. In: A poética clássica. Tradução de Jaime Bruna.Editora Cultrix, São Paulo.

MENDELSOHN, M. 1777. "Über die Empfindungen”. In:

Philosophische Schriften (Erster Theil).Voss, Berlin.

SHAFTESBURY (A.A. Cooper). 1914. Second Characters or The Language of Forms. Edited by Benjamin Rand. Cambridge: University Press.

SULZER, J.G. Allgemeine Theorie der Schönen Künste. Edição fac-simile com base nos originais de 1771 e 1774. 